\title{
IMPLEMENTASI METODE WEIGHTED PRODUCT TERHADAP PENENTUAN PENINDAKAN PENGADUAN DAN METODE SERVQUAL UNTUK MENGETAHUI KEPUASAN PELANGGAN
}

\author{
Ayu Permata Sari ${ }^{1}$ \\ Roni Andarsyah ${ }^{2}$ \\ Rd. Nuraini ${ }^{3}$ \\ Muhamad Hidayat Muhajir ${ }^{4}$ \\ ${ }^{123}$ Program Studi DIV Teknik Informatika, Politeknik Pos Indonesia, Jl. Sari Asih No. 54, Sarijadi, \\ Sukasari, Bandung 40151, Telp. (022) 2009562, Fax. +6222 200 9568, Indonesia \\ ayypermata@gmail.com 1, roniandarsyah@poltekpos.ac.id ${ }^{2}$, nurainiepoltekpos.ac.id ${ }^{3}$
}

\begin{abstract}
ABSTRAK-Layanan pengaduan masyarakat adalah salah satu bentuk partisipasi untuk ikut berperan dalam membangun dan pengawasan terhadap kinerja suatu perusahaan. Dalam proses pengaduan PT. Pos Indonesia, masih mengalami kesulitan dalam menentukan pengaduan yang lebih mendesak, sehingga dalam menentukan pengaduan yang lebih mendesak atau diprioritaskan untuk segera ditindaklanjuti membutuhkan waktu yang lama serta belum tentu hasil yang didapat juga benar. Kesulitan lainnya adalah PT. Pos Indonesia tidak dapat mengetahui layanan apa saja yang telah memuaskan pelanggan dan layanan apa saja yang perlu ditingkatkan. Maka penulis membuat sistem layanan pengaduan agar dapat mempermudah dalam menentukan pengaduan yang diprioritaskan untuk ditindaklanjuti lebih dahulu, dan juga mempermudah PT. Pos Indonesia untuk dapat mengetahui tingkat kepuasan pelanggan terhadap layanan PT. Pos Indonesia. Penelitian ini menggunakan metode Weighted Product yaitu salah satu metode penyelesaian masalah. Dengan menggunakan metode Weighted Product (WP) akan mencari bobot untuk setiap kriteria, kemudian dilakukan proses peringkat yang akan menentukan alternatif optimal dari pengaduan. Metode Weighted Product dapat membantu dalam mengambil keputusan prioritas pengaduan. Dan metode Servqual untuk mengetahui tingkat kepuasan pelanggan dengan ukuran seberapa baik suatu layanan. Hasil dari penelitian ini, mempermudah dalam menentukan pengaduan yang diprioritaskan untuk ditindaklanjuti dan mengetahui tingkat kepuasan pelanggan terhadap layanan PT. Pos Indonesia.
\end{abstract}

Kata Kunci : PT Pos Indonesia, Kepuasan Pelanggan, Kepuasan Layanan Pengaduan, Layanan Pengaduan Pelanggan, Metode Servqual, Metode Weighted Product, Prioritas Pengaduan.

ABSTRACT-The community complaints service is one form of participation for participation in the making, and supervision of companies. In the complaint process PT. Pos Indonesia, it is still difficult in determining which complaints are preferred, so in determining which complaints are more necessary or prioritized for immediate action requires a long time and not necessarily the results obtained are also true. Another difficulty is PT. Pos Indonesia cannot understand what services have satisfied customers, and what services need to be improved. So the authors make a complaint service system so that it can facilitate in determining the priority complaints to be followed up first, and also allows PT. Pos Indonesia to find out the level of customer satisfaction with the services of PT. Pos Indonesia This study uses the Weighted Product method which is one of the problems solving. Using the Weighted Product (WP) method will find the weights for each criterion, then a ranking process will be carried out that will determine the optimal alternative to the complaint. Weighted Product Method can help in the making priority complaints decisions. And the Servqual method to get high levels of customer satisfaction for each service. The results of this study, make it easier to determine complaints that are prioritized for follow-up and find out the level of customer satisfaction with the services of PT. Pos Indonesia

Key Words: PT Pos Indonesia, Customer Satisfaction, Customer Satisfaction, Servqual Method, Weighted Product Method, ComplaintsPriorit 


\section{PENDAHULUAN}

\subsection{Latar Belakang}

PT. Pos Indonesia (Persero) merupakan salah satu Badan Usaha Milik Negara (BUMN [1] yang bergerak di bidang jasa pelayanan jasa pos, jasa keuangan, jasa logistik dan e-bisnis dengan jangkauan operasi hampir di seluruh Indonesia [2]. Paket pos merupakan salah satu jenis produk layanan jasa dari PT. Pos Indonesia (Persero) yang sering digunakan oleh para pelanggan untuk mengirimkan barang ke tempat tujuan. Namun seiring berjalannya waktu, sekarang mulai bermunculan perusahaan jasa pengiriman barang lainnya yang menjadi pesaing PT. Pos Indonesia (Persero). Hal ini mutlak memacu PT. Pos Indonesia untuk meningkatkan kualitas layanan agar memperoleh kepuasan pelanggan dan meningkatkan omset [3]. PT. Pos Indonesia merupakan perusahaan yang salah satu misinya adalah to make profit dituntut untuk memberikan layanan sebaik mungkin, karena tidak dapat dipungkiri lagi bahwa prinsip berhubungan dengan orang lain dan juga memenuhi kebutuhan mereka kuncinya terletak pada kata memberi pelayanan [4]. Konsumen sebagai pengguna barang dan jasa dalam melakukan pembelian banyak dipengaruhi oleh faktor-faktor internal dan eksternal. Faktor-faktor tersebut mempunyai pengaruh yang sangat besar dalam mempengaruhi proses keputusan untuk membeli suatu produk bagi seseorang konsumen [5]. Kepuasan konsumen mencerminkan penilaian terhadap kinerja produk/jasa dalam kaitannya dengan ekspektasi. Untuk itu, kualitas jasa sangat menentukan kepuasan konsumen. Pelanggan yang berkurang atau bahkan hilang, disebabkan oleh pelayanan yang tidak memuaskan [6]. Pengaduan masyarakat merupakan suatu bentuk partisipasi untuk ikut berperan dalam membangun lingkungannya serta sebagai bentuk pengawasan terhadap kinerja instansi pemerintahan [7]. Laporan maupun aspirasi masyarakat dapat dipergunakan sebagai bahan masukan untuk mengevaluasi kebijakan dan peraturan yang telah dibuat atau peraturan yang telah dilaksanakan dan untuk mengetahui masalah yang ada didalam masyarakat secara efektif, cepat, dan up to date serta dapat langsung memberikan solusi dan jalan keluar [8]. Saat ini, PT. Pos Indonesia belum memiliki system layanan pengaduan konsumen. Proses pengaduan yang masih berjalan saat ini adalah konsumen yang ingin menyampaikan keluhan dengan menyampaikan keluhan dikolom komentar salah satu media sosial PT. Pos Indonesia seperti instagram, facebook, twitter [9]. Namun, beberapa keluhan dari konsumen tidak ditanggapi oleh pihak PT. Pos Indonesia. Selain itu, pihak PT. Pos Indonesia tidak dapat merekap data pengaduan terhadap layanan PT. Pos Indonesia karena tidak adanya sistem khusus pengaduan konsumen. Maka dari itu, telah dibuatkan sistem layanan pengaduan untuk mengetahui apa saja keluhan masuk dari pengguna jasa PT. Pos Indonesia. Kemudian, kesulitan selanjutnya adalah mengenai penindakan terhadap pengaduan. Penindakan terhadap pengaduan dilakukan sesuai tanggal masuk pengaduan tersebut, tidak sedikit juga pengaduan yang itu sangat mendesak dan diminta untuk sesegera mungkin untuk ditindak, di karenakan kasus yang diadukan sangat penting. Maka dari itu, perlu adanya prioritas penindakan dari berbagai pengaduan. Dalam memprioritaskan penindakan ditinjau dari 2 kriteria yaitu; kategari pengaduan, topik pengaduan. Dengan demikian akan tercipta suatu prioritas, pengaduan yang akan didahulukan. Dalam menentukan prioritas penindakan pengaduan, diperlukan metode menentukan prioritas atau rangking Berdasarkan masalah di atas, maka dibutuhkan suatu sistem layanan pengaduan yang dapat menjadi wadah para konsumen PT. Pos Indonesia memberikan keluhan atau kritik dan saran terhadap kinerja PT. Pos Indonesia, yang akan membantu monitoring keluhan dari konsumen terkait pelayanan PT. Pos Indonesia. Aplikasi ini akan membantu mengatasi permasalahan pada saat ini yaitu melakukan pengaduan/komplain/kritik/saran kepada pihak PT. Pos Indonesia. Sistem yang akan dibangun bersifat online sehingga kapanpun dan dimanapun konsumen dapat melakukan pengaduan.

\subsection{Permasalahan}

Identifikasi masalah berdasarkan latar belakang adalah sebagai berikut:

1. Bagaimana memproritaskan aduan dengan menggunakan metode Weighted Product?

2. Bagaimana implementasi metode Servqual untuk mengetahui kepuasan pelanggan PT. Pos Indonesia? 


\section{METODOLOGI PENELITIAN}

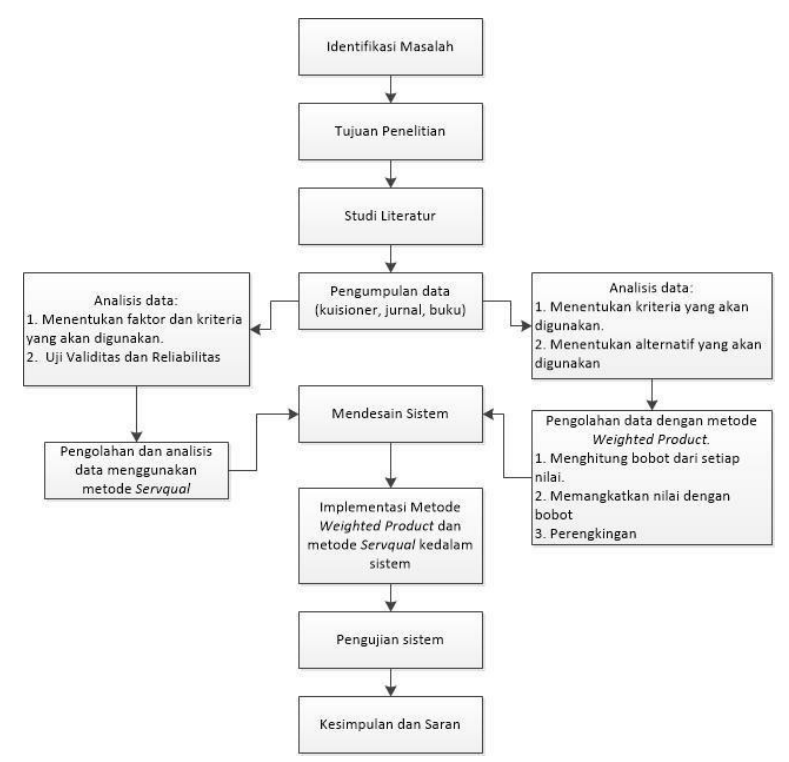

Gambar 2.1 Diagram Alur Metodologi Penelitian

\subsection{Identifikasi Masalah}

Pada tahapan identikasi ini merupakan tahapan awal dari pembuatan laporan Tugas Akhir. Dilakukan pengamatan dan analisis terhadap objek dari perusahaan PT. Pos Indonesia. Berdasarkan analisa tersebut diperoleh kondisi objek lalu kemudian ditetapkan menjadi bentuk permasalahan. Penindakan pengaduan dan kepuasan pelanggan adalah permasalahan yang didapatkan, maka penelitian ini akan membahas bagaimana proses mencari prioritas penindakan pengaduan dan mengetahui kepuasan pelanggan PT. Pos Indonesia. Kemudian akan ditentukan rumusan masalah, tujuan sampai ke manfaat. Ini bertujuan agar proses pengerjaan laporan Tugas Akhir ini berjalan lebih maksimal.

\subsection{Tujuan Penelitian}

Tujuan penelitian merupakan pernyataan mengenai apa yang akan dihasilkan atau dicapai oleh peneliti. Dalam penelitian ini akan ditentukan tujuan untuk membuat sistem layanan pengaduan PT. Pos Indonesia. Dalam hal ini, untuk mengetahui pengaduan mana yang akan ditangani lebih dahulu dan mengevaluasi kepuasan pelanggan PT. Pos Indonesia. Tujuan penelitian tergantung dengan pada jenis penelitian dan masalah yang akan diteliti. Oleh sebab itu, tujuan penelitian harus konsisten dengan masalah yang telah dirumuskan.

\subsection{Studi Literatur}

Setelah masalah penelitian dirumuskan dan menentukan tujuan penelitian, maka langkah selanjutnya dalam proses penelitian ini adalah mencari teori-teori dan konsepkonsep hasil penelitian yang dapat dijadikan sebagai landasan teori untuk pelaksanaan penelitian yang berkaitan dengan judul. Studi literatur ini diperlukan dalam membantu proses penelitian sehingga peneliti dapat memperoleh berbagai sumber yang terkait dalam proses penelitian sehingga penelitian ini mempunyai teori yang kuat. Dalam hal ini, peneliti memperoleh informasi melalui buku, jurnal serta laporan penelitian untuk memperkuat teori dalam proses penelitian ini.

\subsection{Pengumpulan Data}

Peneliti menentukan jenis data pada panelitian yaitu data primer dan data sekunder.

2.4.1 Data Primer. Pada data primer, peneliti menggunakan data primer yaitu data yang didapat dari sumber pertama. Dalam hal ini peneliti menyebarkan kuesioner kepada masyarakat terkait dengan kepuasan pelanggan terhadap layanan PT. Pos Indonesia.

2.4.2 Data Sekunder. Pada data sekunder, peneliti menggunakan data-data referensi dari beberapa buku, jurnal, atau artikel mengenai penindakakan penanganan pengaduan dan kepuasan pelanggan dan juga penerapan metode Weighted Product dan metode

\subsection{Uji Validitas}

Uji validitas dimaksudkan untuk mengetahui apakah setiap instrumen pertanyaan yang terdapat pada kuesioner sebagai alat pengumpul data mempunyai kevalidan, sehingga dapat dilihat mana instrumen yang layak dan tidak layak untuk dijadikan instrumen pada kuesioner. Suatu instrumen dinyatakan valid apabila mampu mengukur apa yang diinginkan dan kriteria instrumen data telah valid jika koefisien korelasi product moment $<0,273$ ( $\mathrm{r}$ table $\mathrm{n}=50$ bernilai 0,273). Dalam penelitian ini menggunakan bantuan program SPSS. Berikut ini merupakan hasil uji validitas pada tingkat kinerja kualitas pelayanan. Berdasarkan tabel uji validitas pada tingkat kinerja diatas, dapat diketahui bahwa keseluruhan instrumen yang berjumlah 13 pernyataan dinyatakan valid karena nilainya diatas $<0.273$. Dengan demikian maka penelitian ini dapat dilanjutkan pada analisis berikutnya. 


\subsection{Uji Reliabilitas}

Uji reliabilitas dilakukan untuk mengukur sejauh mana suatu hasil pengukuran relatif konsisten. Metode yang digunakan dalam menentukan tingkat reliabilitas adalah dengan koefisien Cronbach Alpha sebesar <0,60. Uji reliabilitas ini menggunakan alat bantu program SPSS. Berikut merupakan hasil uji reliabilitas dapat dilihat pada tabel IV.2 Berdasarkan tabel mengenai uji reliabilitas diatas menunjukkan bahwa tingkat kinerja diperoleh nilai koefisien Cronbachs Alpha sebesar 0,870.Maka sesuai dengan kriteria nilai tersebut dinyatakan reliabel karena lebih dari $<0,60$ yang berarti penelitian ini dapat dilanjutkan

\subsection{Analisis Data (Metode Servqual)}

Pada tahap ini, data yang telah ditentukan akan dianalisis guna untuk melengkapi dan memenuhi kebutuhan mengetahui kepuasan pelanggan menggunakan metode Servqual. Faktor dan kriteria dalam penelitian tentang kualitas pelayanan ini mengacu kepada 5 dimensi Servqual yaitu:
2.7.1 Tangibles (bukti terukur)
2.7.2 Reliability (keandalan)
2.7.3 Responsiveness (daya tanggap)
2.7.4 Assurance (jaminan)
2.7.5 Empathy (empati)

\subsection{Analisis Data (Metode Weigted Product)}

Pada tahap ini, data yang telah ditentukan akan dianalisis guna untuk melengkapi dan memenuhi kebutuhan mencari prioritas penangan pengaduan menggunakan metode Weighted Product:

2.8.1 Menentukan kriteria yang akan digunakan dalam pemilihan pengaduan yang akan direkomendasikan untuk prioritas penanganan dengan data yang didapatkan dari PT. Pos Indonesia. Pada penelitian ini kriteria yang digunakan yaitu kategori pengaduan, dan topik pengaduan.

2.8.2 Menentukan alternatif yang akan digunakan sebagai bahan penelitian di dalam pemilihan prioritas penangan pengaduan sesuai dengan data yang didapatkan dari PT. Pos Indonesia, alternatif yang digunakan yaitu laporan pengaduan yang terdapat didalam sistem.

2.8.3 Pengolahan Data Menggunakan Metode Servqual Setelah data dianalisis, kemudian data diproses dengan menggunakan metode Servqual dengan langkah sebagai berikut:

2.8.4 Teknik pengolahan data yang digunakan dalam penelitian ini adalah analisis data seperti uji validasi dan reliabilitas menggunakan SPSS dan mengintegrasikan pembobotan dan perangkingan dalam metode Servqual.

2.8.5 Data yang telah dikumpulkan akan diolah untuk dapat menemukan rata-rata skor persepsi dan harap dari pelanggan mengenai kualitas layanan PT. Pos Indonesia.

2.8.6 Menghitung gap antara persepsi dan harapan dengan cara mengurangkan nilai persepsi dengan nilai skor harapan.

2.8.7 Setelah didapat nilai gap selanjutnya akan dihitung skor Servqual dengan cara menghitung rata-rata gap antara kriteria.

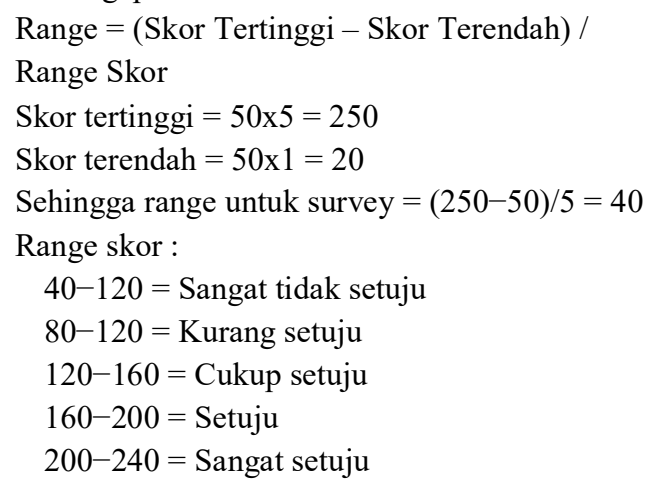

\subsection{Pengolahan Data Menggunakan Metode Weighted Product}

Setelah data dianalisis, kemudian data diproses dengan menggunakan metode Weighted Product dengan langkah sebagai berikut:

\subsubsection{Menghitung bobot dari setiap nilai kriteria.}

Tabel. 3.1 Nilai Bobot

\begin{tabular}{|c|l|}
\hline Bobot & Nilai \\
\hline 5 & Sangat Penting \\
\hline 4 & Penting \\
\hline 3 & Cukup Penting \\
\hline 2 & Kurang Penting \\
\hline 1 & Tidak Penting \\
\hline
\end{tabular}

Tabel. 3.2 Bobot Kriteria

\begin{tabular}{|l|c|c|}
\hline No & Kriteria & Bobot \\
\hline 1. & Kategori Pengaduan & 5 \\
\hline
\end{tabular}




\begin{tabular}{|l|l|l|}
\hline 2. & Topik Pengaduan & 4 \\
\hline
\end{tabular}

Tabel. 3.3 Bobot Sub Kriteria

\begin{tabular}{|c|c|c|c|}
\hline No & Kriteria & Sub Kriteria & Bobot \\
\hline \multirow{3}{*}{1.} & \multirow{3}{*}{$\begin{array}{l}\text { Kategori } \\
\text { Pengaduan }\end{array}$} & Kategori Berat & 5 \\
\hline & & Kategori Sedang & 4 \\
\hline & & Kategori Ringan & 3 \\
\hline \multirow{6}{*}{2.} & \multirow{6}{*}{$\begin{array}{l}\text { Topik } \\
\text { Pengaduan }\end{array}$} & Kehilangan & 5 \\
\hline & & Belum Diterima & 4 \\
\hline & & Keterlambatan & 3 \\
\hline & & $\begin{array}{l}\text { Kiriman Tidak } \\
\text { Utuh }\end{array}$ & 2 \\
\hline & & Layanan Pos & 1 \\
\hline & & Lainnya & 1 \\
\hline
\end{tabular}

Bobot dari data kriteria tersebut akan dinormalisasikan atau perbaikan nilai bobotnya dengan menggunakan persamaan di bawah ini:

$$
W_{j}=\frac{W_{j}}{\sum W_{j}}
$$

Menghitung nilai normalisasi bobot atau perbaikan bobot $(\mathrm{Wj})$ berdasarkan nilai prioritas bobot setiap kriteria yang sudah ditentukan. Dari persamaan (1) maka nilai bobot yang dimiliki masing-masing kriteria dibagi dengan jumlah dari semua bobot kriteria. Maka, untuk setiap kriteria didapatkan hasil bobot sebagai berikut: Nilai awal $\mathrm{W}=[5,4]$

a) Untuk normalisasi bobot kriteria Kategori Pengaduan (K1)

$\mathrm{K} 1=5 /(5+4)=5 / 9=0,56$

b) Untuk normalisasi bobot kriteria Topik Pengaduan (K2)

$\mathrm{K} 2=4 /(5+4)=5 / 9=0,44$

c) Untuk normalisasi bobot subkriteria ketegori berat

$\mathrm{Wj}$ kategori berat $=5 /(5+4+3)=5 / 12=0,417$

d) Untuk normalisasi bobot subkriteria kategori sedang

$\mathrm{Wj}$ kategori sedang $=4 /(5+4+3)=4 / 12=0,333$

e) Untuk normalisasi bobot subkriteria kategori berat $\mathrm{Wj}$ kategori ringan $=3 /(5+4+3)=3 / 12=0,5$

f) Untuk normalisasi bobot subkriteria kehilangan $\mathrm{Wj}$ kehilangan $=5 /(5+4+3+2+1+1)=5 / 16=$ 0,3125

g) Untuk normalisasi bobot subkriteria belum diterima

$\mathrm{Wj}$ belum diterima $=4 /(5+4+3+2+1+1)=4 / 16=$ 0,25

h) Untuk normalisasi bobot subkriteria keterlambatan $\mathrm{Wj}$ keterlambatan $=3 /(5+4+3+2+1+1)=3 / 16=$ 0,1875

i) Untuk normalisasi bobot subkriteria kiriman tidak utuh

$\mathrm{Wj}$ kiriman tidak utuh $=2 /(5+4+3+2+1+1)=2 / 16$ $=0,125$

j) Untuk normalisasi bobot subkriteria layanan pos $\mathrm{Wj}$ layanan pos $=1 /(5+4+3+2+1+1)=1 / 16=$ 0,0625

k) Untuk normalisasi bobot subkriteria lainnya $\mathrm{Wj}$ lainnya $=1 /(5+4+3+2+1+1)=1 / 16=$

2.9.2 Memangkatkan nilai kriteria dengan bobot. Nilai Kriteria Besar Gaji (K1) = 0,56 Jadi bobot global untuk Subkriteria Kategori Pengaduan (K1) adalah sebagai berikut:

a) Kategori Berat $=0,417 * 0,56=0,2315$

b) Kategori Sedang $=0,333 * 0,56=0,1852$

c) Kategori Ringan $=0,25 * 0,56=0,1389$

Nilai Kriteria Topik Pengaduan $(\mathrm{K} 2)=0,44$ Jadi bobot global untuk Subkriteria Topik Pengaduan (K2) adalah sebagai berikut:

a) Kehilangan $=0,3125 * 0,44=0,1389$

b) Belum Diterima $=0,25 * 0,44=0,1111$

c) Kiriman Tidak Utuh $=0,1875 * 0,44=0,0833$

d) Keterlambatan $=0,125 * 0,44=0,0556$

e) Layanan Pos $=0,0625 * 0,56=0,0278$

f) Lainnya $=0,0625 * 0,56=0,0278$

g) Perengkingan hasil pembobotan nilai kriteria.

\subsubsection{Mendesain Sistem}

Tujuan : menjelaskan perancangan sistem UML Masukan : data sekunder

Metode : Unied Modelling Language

Keluaran : Usecase Diagram

Perancangan yang akan dibuat menggunakan Object Oriented Unied Modelling Language (UML) terdiri dari use case diagram yang akan dijelaskan berupa aktor dan fungsi masing-masing aktor dan sistem.

2.9.4 Implementasi Metode Servqual dan Weighted Product

Pada tahap ini dilakukan perancangan code atau script dan pengembangan solusi berdasarkan tujuan penelitian dengan menggunakan sistem atau aplikasi yang 
menerapkan metode weighted product untuk menentukan prioritas penangan pengaduan dan metode Servqual untuk mengetahui tingkat kepuasan pelanggan PT. Pos Indonesia. Pada tahap pembuatan (construction) ini merupakan proses pembuatan sistem sesuai dengan kebutuhan yang telah dianalisis sebelumnya. Untuk dapat dimengerti oleh mesin, dalam hal ini adalah komputer, maka desain tadi harus diubah bentuknya menjadi bentuk yang dapat dimengerti oleh mesin, yaitu ke dalam bahasa pemrograman melalui proses coding. Tahapan ini akan menampilkan hasil berupa perhitungan yang telah dilakukan pembobotan kriteria dan menentukan alternatif yang nantinya akan mendapatkan perengkingan dari hasil penerapan metode Weighted Product dan untuk metode Servqual data yang telah dikumpulkan akan diolah untuk dapat menemukan rata-rata skor persepsi dan harap dari pelanggan mengenai kualitas layanan PT. Pos Indonesia pada sistem yang akan dibangun. Ini bertujuan agar analisa lebih terukur dalam menentukan prioritas penangan pengaduan dan mengetahui tingkat kepuasan pelanggan terhadap layanan PT. Pos Indonesia.

\subsubsection{Pengujian Sistem}

Setelah implementasi sistem atau pengerjaan sistem selesai, maka saatnya dilakukan percobaan terhadap kinerja sistem yang sudah dibuat. Testing atau pengujian adalah proses untuk memastikan bahwa aplikasi yang dikembangkan bebas dari kesalahan, dilakukan testing (uji coba) pada aplikasi tersebut. Masalah yang sering terjadi adalah dalam salah satu modul sering tidak bisa memanggil modul lain. Tahap ini perlu melakukan coding ulang terhadap kesalahan sampai error dapat berjalan lagi. Dari perancangan sistem ini dilakukan pengujian Black Box. Pengujian dimaksudkan untuk mengetahui apakah fungsifungsi, masukan dan keluaran dari perangkat lunak sesuai dengan spesikasi yang dibutuhkan

\subsubsection{Kesimpulan dan Saran}

Kesimpulan yang didapatkan dari proses perhitungan menggunakan Metode Weighted Product dan metode Servqual. Hasil akhir yang diperoleh dari seluruh tahapan, adalah sistem yang dibuat menampilkan hasil perengkingan prioritas penanganan pengaduan dan hasil tingkat kepuasan pelanggan PT. Pos Indonesia.

Kesimpulan dan Saran yang terangkum bertujuan untuk menjawab permasalan penelitian.

\section{HASIL DAN PEMBAHASAN}

\subsection{Metode Weighted Product}

\subsubsection{Data Awal Pengaduan}

\begin{tabular}{|c|c|c|l|l|}
\hline \multirow{2}{*}{ Alternatif } & \multicolumn{3}{|c|}{ Kriteria } & \multirow{2}{*}{ Topik } \\
\cline { 2 - 4 } & K1 & K2 & Kategori & \multicolumn{1}{|c|}{ Tohilang } \\
\hline P1 & 5 & 5 & $\begin{array}{l}\text { Kategori } \\
\text { Berat }\end{array}$ & $\begin{array}{l}\text { Kehilan } \\
\text { an }\end{array}$ \\
\hline P3 & 5 & 1 & $\begin{array}{l}\text { Kategori } \\
\text { Ringan }\end{array}$ & $\begin{array}{l}\text { Layanan } \\
\text { Pos }\end{array}$ \\
\hline & & 2 & $\begin{array}{l}\text { Kategori } \\
\text { Beat }\end{array}$ & $\begin{array}{l}\text { Keterlam } \\
\text { batan }\end{array}$ \\
\hline P4 & 4 & 1 & $\begin{array}{l}\text { Kategori } \\
\text { Sedang }\end{array}$ & $\begin{array}{l}\text { Layanan } \\
\text { Pos }\end{array}$ \\
\hline P5 & 5 & 4 & $\begin{array}{l}\text { Kategori } \\
\text { Berat }\end{array}$ & $\begin{array}{l}\text { Belum } \\
\text { Diterima }\end{array}$ \\
\hline P6 & 5 & 2 & $\begin{array}{l}\text { Kategori } \\
\text { Berat }\end{array}$ & $\begin{array}{l}\text { Keterlam } \\
\text { batan }\end{array}$ \\
\hline P7 & 3 & 2 & $\begin{array}{l}\text { Kategori } \\
\text { Sedang }\end{array}$ & $\begin{array}{l}\text { Keterlam } \\
\text { batan }\end{array}$ \\
\hline
\end{tabular}

\subsubsection{Perhitungan Vektor S}

Menentukan nilai vektor $\mathrm{S}$ dengan mengalikan seluruh kriteria dengan alternatif hasil normalisasi/perbaikan bobot yang berpangkat positif untuk kriteria keuntungan dan yang berpangkat negatif. Proses kuadratkan data alternatif dengan bobot global masing masing subkriteria yang telah didapatkan. Perhitungan vektor S menggunakan persamaan dibawah ini.

\subsubsection{Maka untuk perhitungan vektor $S$ setiap alternatif adalah}

a) $\mathrm{S} 1=(50,2315)(50,1389)=$

$(1.410036)(1.250509)=1.763263$

b) $\mathrm{S} 2=(50,2315)(10,0278)=(1.164856)(1)=$ 1.164856

c) $\mathrm{S} 3=(50,2315)(20,0556)=$

$(1.410036)(1.039291)=1.465438$

d) $\mathrm{S} 4=(40,1852)(10,0278)=(1.292353)(1)=$ 1.292353

e) $\mathrm{S} 5=(50,2315)(40,1111)=$ $(1.410036)(1.166511)=1.644822$

f) $\mathrm{S} 6 \quad=(50,2315)(20,0556)$ $(1.410036)(1.039291)=1.465438$

g) $\mathrm{S} 7=(30,1389)(20,0556)=$ $(1.164856)(1.039291)=1.210624$

\subsubsection{Perhitungan Vektor V}

Menentukan nilai vektor $\mathrm{V}$ yang akan digunakan untuk perangkingan dari masingmasing jumlah nilai vektor 
$\mathrm{S}$ dengan jumlah seluruh nilai vektor $\mathrm{S}$.
a) $\mathrm{V} 1=(1.763263) /(10.006793)=0.176207$
b) $\mathrm{V} 2=(1.164856) /(10.006793)=0.116496$
c) $\mathrm{V} 3=(1.465438) /(10.006793)=0.146444$
d) $\mathrm{V} 4=(1.292353) /(10.006793)=0.129148$
e) $\mathrm{V} 5=(1.644822) /(10.006793)=0.164371$
f) $\mathrm{V} 6=(1.465438) /(10.006793)=0.146444$
g) $\mathrm{V} 7=(1.210624) /(10.006793)=0.12098$

\subsubsection{Hasil Akhir}

Total penilaian dari seluruh kriteria dan subkriteria diperoleh $\mathrm{P} 1=0.176207, \mathrm{P} 2=0.116496$, $\mathrm{P} 3=0.146444, \mathrm{P} 4=0.129148, \mathrm{P} 5=0.164371, \mathrm{P} 6=$ $0.146444, \mathrm{P} 7=0.12098$.

\begin{tabular}{|c|c|c|c|c|c|}
\hline \multirow{2}{*}{$\begin{array}{c}\text { Alternat } \\
\text { if }\end{array}$} & \multicolumn{4}{|c|}{ Kriteria } & \multirow{2}{*}{$\begin{array}{l}\text { Pri } \\
\text { orit } \\
\text { as }\end{array}$} \\
\hline & $\begin{array}{c}\mathrm{K} \\
1 \\
\end{array}$ & $\begin{array}{l}\mathrm{K} \\
2\end{array}$ & Kategori & Topik & \\
\hline P1 & 5 & 5 & $\begin{array}{l}\text { Kategori } \\
\text { Berat }\end{array}$ & $\begin{array}{l}\text { Kehilan } \\
\text { gan }\end{array}$ & 1 \\
\hline $\mathrm{P} 2$ & 3 & 1 & $\begin{array}{l}\text { Kategori } \\
\text { Ringan }\end{array}$ & $\begin{array}{l}\text { Layana } \\
\text { n Pos }\end{array}$ & 7 \\
\hline P3 & 5 & 2 & $\begin{array}{l}\text { Kategori } \\
\text { Beat }\end{array}$ & $\begin{array}{l}\text { Keterla } \\
\text { mbatan }\end{array}$ & 3 \\
\hline P4 & 4 & 1 & $\begin{array}{l}\text { Kategori } \\
\text { Sedang }\end{array}$ & $\begin{array}{l}\text { Layana } \\
\mathrm{n} \text { Pos }\end{array}$ & 5 \\
\hline P5 & 5 & 4 & $\begin{array}{l}\text { Kategori } \\
\text { Berat }\end{array}$ & $\begin{array}{l}\text { Belum } \\
\text { Diterim } \\
\mathrm{a}\end{array}$ & 2 \\
\hline P6 & 5 & 2 & $\begin{array}{l}\text { Kategori } \\
\text { Berat }\end{array}$ & $\begin{array}{l}\text { Keterla } \\
\text { mbatan }\end{array}$ & 4 \\
\hline P7 & 3 & 2 & $\begin{array}{l}\text { Kategori } \\
\text { Sedang }\end{array}$ & $\begin{array}{l}\text { Keterla } \\
\text { mbatan }\end{array}$ & 6 \\
\hline
\end{tabular}

\subsection{Metode Servqual}

\subsubsection{Hasil Dimensi Tangible}

\begin{tabular}{|c|c|c|c|c|c|c|c|}
\hline \multicolumn{2}{|c|}{ Dimensi } & \multicolumn{5}{|c|}{ Kualitas } & Tota \\
\cline { 2 - 7 } Tangibl & 5 & 4 & 3 & 2 & 1 & 1 \\
\hline e & 1 & 24 & 1 & 6 & 1 & 0 & 50 \\
\cline { 2 - 7 } & & & 9 & & & & \\
\hline & Nila & 12 & 7 & 1 & 2 & 0 & 216 \\
& i & 0 & 6 & 8 & & & \\
\cline { 2 - 7 } & 2 & 4 & 2 & 1 & 1 & 1 & 50 \\
& & & 2 & 3 & 0 & & \\
\cline { 2 - 7 } & Nila & 20 & 8 & 3 & 2 & 1 & 169 \\
& i & & 8 & 9 & 0 & & \\
\hline
\end{tabular}

\subsubsection{Hasil Dimensi Empathy}

$$
\text { Dimensi }
$$

Kualitas

Total

\begin{tabular}{|c|c|c|c|c|c|c|c|}
\hline \multicolumn{2}{|c|}{} & 5 & 4 & 3 & 2 & 1 & \\
\hline \multirow{4}{*}{ Empathy } & 1 & 9 & 20 & 14 & 17 & 0 & 50 \\
\cline { 2 - 8 } & Nilai & 45 & 80 & 42 & 14 & 0 & 181 \\
\cline { 2 - 8 } & 2 & 9 & 17 & 16 & 8 & 0 & 50 \\
\cline { 2 - 8 } & Nilai & 45 & 68 & 48 & 16 & 0 & 177 \\
\hline
\end{tabular}

\subsubsection{Hasil Dimensi Reliability}

\begin{tabular}{|l|c|c|c|c|c|c|c|}
\hline \multicolumn{2}{|c|}{ Dimensi } & \multicolumn{5}{|c|}{ Kualitas } & Tota \\
\cline { 2 - 7 } Reliabilit & 5 & 4 & 3 & 2 & 1 & 1 \\
\hline y & 5 & 2 & 1 & 6 & 0 & 50 \\
\cline { 2 - 7 } & & & 4 & 5 & & & \\
\hline & Nila & 2 & 9 & 4 & 1 & 0 & 178 \\
& $\mathrm{i}$ & 5 & 6 & 5 & 2 & & \\
\cline { 2 - 7 } & 2 & 1 & 1 & 1 & 6 & 0 & 50 \\
& & 3 & 9 & 2 & & & \\
\cline { 2 - 7 } & Nila & 6 & 7 & 2 & 1 & 0 & 189 \\
& $\mathrm{i}$ & 5 & 6 & 6 & 2 & & \\
\hline
\end{tabular}

\subsubsection{Hasil Dimensi Responsiveness}

\begin{tabular}{|l|c|c|c|c|c|c|c|}
\hline \multicolumn{2}{|c|}{ Dimensi } & \multicolumn{5}{|c|}{ Kualitas } \\
\cline { 3 - 7 } \\
\cline { 2 - 7 } $\begin{array}{l}\text { Responsien } \\
\text { ess }\end{array}$ & 5 & 4 & 3 & 2 & 1 & al \\
\hline & & 2 & 26 & 1 & 7 & 0 & 50 \\
\cline { 2 - 7 } & Nil & 1 & 10 & 4 & 1 & 0 & 173 \\
& ai & 0 & 4 & 5 & 4 & & \\
\cline { 2 - 7 } & 2 & 5 & 22 & 1 & 8 & 0 & 50 \\
& & & & 5 & & & \\
\cline { 2 - 7 } & Nil & 2 & 88 & 4 & 1 & 0 & 174 \\
& ai & 5 & & 5 & 6 & & \\
\hline
\end{tabular}

\subsubsection{Hasil Dimensi Assurance}

\begin{tabular}{|c|c|c|c|c|c|c|c|}
\hline \multicolumn{2}{|c|}{ Dimensi } & \multicolumn{5}{|c|}{ Kualitas } & \multirow{2}{*}{$\begin{array}{c}\text { Tota } \\
1\end{array}$} \\
\hline & & 5 & 4 & 3 & 2 & 1 & \\
\hline \multirow{7}{*}{$\begin{array}{l}\text { Assuranc } \\
\mathrm{e}\end{array}$} & 1 & 3 & 35 & 8 & 4 & 0 & 50 \\
\hline & Nila & 1 & 14 & 2 & 8 & 0 & 187 \\
\hline & 1 & 5 & 0 & 4 & & & \\
\hline & 2 & 3 & 28 & 1 & 5 & 0 & 50 \\
\hline & & & & 4 & & & \\
\hline & Nila & 1 & 11 & 4 & 1 & 0 & 179 \\
\hline & $\mathrm{i}$ & 5 & 2 & 2 & 0 & & \\
\hline
\end{tabular}

3.2.7 Hasil Dimensi Kepuasan Pelanggan

\begin{tabular}{|c|c|c|c|c|c|c|c|}
\hline \multicolumn{2}{|c|}{ Dimensi } & \multicolumn{5}{c|}{ Kualitas } & Tota \\
\cline { 3 - 7 } \multicolumn{2}{|c|}{} & 5 & 4 & 3 & 2 & 1 & 1 \\
\hline \multirow{2}{*}{ Kepuasa } & 1 & 1 & 21 & 8 & 4 & 0 & 50 \\
\hline
\end{tabular}




\begin{tabular}{|c|c|c|c|c|c|c|c|}
\hline \multirow{9}{*}{$\begin{array}{l}\mathrm{n} \\
\text { Pelangga } \\
\mathrm{n}\end{array}$} & Nila & 8 & \multirow[t]{2}{*}{84} & 2 & \multirow[t]{2}{*}{9} & \multirow[t]{2}{*}{0} & \multirow[t]{2}{*}{201} \\
\hline & $\mathrm{i}$ & 5 & & 4 & & & \\
\hline & 2 & $\begin{array}{l}1 \\
2\end{array}$ & 24 & $\begin{array}{l}1 \\
0\end{array}$ & 4 & 0 & 50 \\
\hline & Nila & 6 & 96 & 3 & 8 & 0 & 194 \\
\hline & $\mathrm{i}$ & 0 & & 0 & & & \\
\hline & 3 & 8 & 27 & 1 & 5 & 0 & 50 \\
\hline & & & & 0 & & & \\
\hline & Nila & 4 & 10 & 3 & 1 & 0 & 188 \\
\hline & $\mathrm{i}$ & 0 & 8 & 0 & 0 & & \\
\hline
\end{tabular}

\subsubsection{Hasil Akhir}

Berdasarkan data diatas dapat dilihat bahwa pelanggan cukup setuju dengan kualitas layanan, hal itu dibuktikan dengan nilai persepsi pelanggan terhadap atribut tersebut. Untuk pertanyaan (1) diperoleh nilai sebesar 201 yang berarti pelanggan sangat setuju karena pada range 200 - 240. Untuk pertanyaan (2) diperoleh nilai 194 yang berarti pelanggan setuju karena berada pada range 160 200. Untuk pertanyaan (3) diperoleh nilai 188 yang berarti pelanggan setuju karena berada pada range 160 - 200.

\section{KESIMPULAN DAN SARAN}

\subsection{Kesimpulan}

Dengan adanya aplikasi layanan pengaduan PT. Pos Indonesia ini telah memberikan solusi untuk dapat menampung keluhan pelanggan, mengetahui keluhan apa saja yang masuk ke dalam sistem sehingga termonitoring dan terkomputerisasi.

\subsection{Saran}

Sistem informasi ini hanya dibangun berbasis website, sehingga di harapkan ke depannya dapat dikembangkan. Pada penelitian berikutnya, diharapkan agar bisa dikomparasi dengan menggunakan metode lainnya untuk menghasilkan suatu penelitian yang lebih baik.

\section{DAFTAR PUSTAKA}

[1] I. Alifian and M. Rahardjo, "Analisis pengaruh job insecurity, kepuasan kerja, dan komitmen organisasi terhadap keinginan berpindah karyawan (studi pada karyawan outsourcing pt. pos indonesia cabang kudus)," Diponegoro Journal of Management, pp. 142-149, 2016.

[2] J. K. Sitinjak, A. F. Santoso, and R. Hanafi, "Penilaian terhadap penerapan proses it governance menggunakan cobit versi 5 pada domain bai untuk pengembangan aplikasi studi kasus ipos di pt. pos indonesia," eProceedings of Engineering, vol. 2, no. 2, 2015.

[3] M. Sundjaya, "Sistem pengolahan dan pendistribusian paket pos di bagian paket kantor pos solo 57100," 2012.

[4] N. S. Purba, "Analisis faktor-faktor yang mempengaruhi kinerja karyawan (studi kasus pada pt. pos indonesia bandung)," Ph.D. dissertation, Universitas Kristen Maranatha, 2016.

[5] E. Hidayati, "Analisis kualitas pelayanan dan pengaruhnya terhadap loyalitas pelanggan (studi kasus pada pt. pos indonesia (persero) kantor pos lawang)," Jurnal Manajemen Pemasaran Modern, pp. 81-90, 2010.

[6] P. S. Empat, N. Martono, and M. P. Kuantitatif, "Alma, b.(2007). manajemen pemasaran dan pemasaran jasa. bandung: $\mathrm{Cv}$ alfabeta. anugraha, w., \& sitohang, s.(2015). pengaruh produk, harga, promosi, dan merek terhadap keputusan pembelian ulang. jurnal ilmu dan riset manajemen vol. 4, no 10.” Jurnal EMBA Vol, vol. 2, no. 3, pp. 1550-1562.

[7] D. R. Prasetya, "Analisis pengelolaan pengaduan masyarakat dalam rangka pelayanan publik (studi pada dinas komunikasi dan informatika kota malang)," Jurnal Administrasi Publik, vol. 1, no. 6, pp. 11511158, 2013.

[8] W. A. Yohanitas, T. H. Prayitno et al., "Pengelolaan pengaduan masyarakat kota bekasi (bekasi city public complaints management)," Jurnal Borneo Administrator, vol. 10, no. 3, 2014 